\title{
$M$ cells are involved in pathogenesis of human contact lens-associated giant papillary conjunctivitis
}

\author{
Xingwu Zhong ${ }^{1}$, Hongshan $\mathrm{Liu}^{1}$, Aijun $\mathrm{Pu}^{1}$, Xuefeng $\mathrm{Xia}^{2}$ and Xiaodong $\mathrm{Zhou}^{2}$ \\ ${ }^{1}$ Zhongshan Ophthalmic Center and State Key Laboratory of Ophthalmology, Sun Yat-sen University, \\ Guangzhou 510060, China \\ ${ }^{2}$ Department of Medicine, University of Texas Health Science Center at Houston, TX, USA
}

Received: 2006.11.29, Accepted: 2006.02.21, Published online first: 2007.06.08

\begin{abstract}
Introduction: The objective was to study the pathogenesis of contact lens-associated giant papillary conjunctivitis (CL-GPC). Materials and Methods: Twenty-one biopsies of conjunctival giant papillae were obtained from soft contact lens wearers. The tissues were fixed in $4 \%$ paraformaldehyde and embedded in paraffin. Sections of $5 \mu \mathrm{m}$ thickness were used for studies of histology and immunohistochemistry of pan-B and pan-T cell distributions.

Results: Conjunctival epitheliums on the top of conjunctiva-associated lymphoid tissue typically lacked goblet cells. Lymphocytes from underlying lymphoid follicle were pressed into intra-epithelial "pockets" formed through epithelial invagination. Under the follicle-associated epithelium, pan-B cells were mostly gathered in the central folliclar area and intraepithelial pockets, while CD3-positive T cells were predominantly distributed in parafolliclar region, but only a few in the intraepithelial pockets.

Conclusions: Membranous epithelial cells (M cells) play a key role in the pathogenesis of CL-GPC for the binding and translocation of antigen and pathogen.
\end{abstract}

Key words: M cells, contact lens-associated giant papillary conjunctivitis.

Corresponding authors: Xingwu Zhong, Zhongshan Ophthalmic Center and State Key Laboratory of Ophthalmology, Sun Yat-sen University, Guangzhou 510060, China, e-mail: xingzh88@hotmail.com, or Xiaodong Zhou, Department of Medicine, University of Texas Health Science Center at Houston, Houston, TX 77030, USA, fax: +1 713 500-0580, e-mail: xiaodong.zhou@uth.tmc.edu

\section{INTRODUCTION}

Human contact lens-associated giant papillary conjunctivitis (CL-GPC) is a common condition frequently seen in patients who wear soft contact lens, especially those with hydrogel contact lenses. It is one of the most common reasons for contact lens intolerance and discontinuation of contact lens wear. For many years it has been speculated that CL-GPC is related to mechanical and immune mechanisms $[1,2,7,12,13,34,36]$. However, the pathogenesis of CL-GPC is still unknown.

Mucosa-associated lymphoid tissue (MALT) represents a part of the immune system located at mucosal surfaces. Previous studies suggested that MALT was mainly composed of follicle-associated epithelium (FAE) and lymphoid follicles [6, 8]. In lymphoid follicles, B cells are predominantly distributed in the center of the follicle, while $\mathrm{T}$ cells are in the parafolliclar regions to either side of the center of the follicle. Lymphoid follicles create dome-like protrusions into the epithelial surface $[3,17,32]$. The FAE on top of these domes is typically free of all mucin-secreting goblet cells. The absence of a surface coat of mucus promotes free access to a cell type known as the $\mathrm{M}$ cell (membranous epithelial cell). Studies showed that M cells are essential participants in immunological receptivity phenomena of most mucosae and specialized for the binding, uptake, and translocation of soluble and particulate antigens, pathogens, and macromolecular materials [21, 22, 25, 26, 29]. M cells exhibit a distinctive morphological and physiological phenotype and are typically found in the epithelium overlying MALT. The basolateral membrane of the $\mathrm{M}$ cells is deeply invaginated to form intra-epithelial pockets filled with lymphocytes and macrophages. The invaginations result in only a thin band of cytoplasm separating the apical 
membrane from the basolateral membrane pocket. Antigens and pathogens traversing the cells within vacuoles travel this short distance before they are discharged into the packet space, where they are free to be phagocytosed by macrophages and dendritic cells within the pocket and follicle.

The purpose of this paper is to investigate the presence of $\mathrm{M}$ cells in CL-GPC and to understand the potential mechanisms for CL-GPC.

\section{MATERIALS AND METHODS}

\section{Specimen preparation}

All patients diagnosed as having CL-GPC were those who complained of discomfort, itching, mucous discharge, or foreign body sensation and met one of the following criteria: 1) well-developed papillae of $1 \mathrm{~mm}$ or more in diameter in the upper tarsal conjunctiva after wearing soft contact lens or 2) the hallmark signs of enlarging papillae accompanied by redness of the upper palpebral conjunctiva after wearing soft contact lens for over two years. Conjunctival papillae and follicles $(n=21)$ were obtained through biopsies from the upper tarsal conjunctiva of CL-GPC patients diagnosed at the Zhongshan Ophthalmic Center, Sun Yat-sen University. The average age of the patients was $20.3 \pm 8.5$ years and the sex distribution was 13:7 (female to male). All experimental protocols in this study were approved by the Governmental Agency in China.

Briefly, to minimize trauma to the conjunctiva, conjunctiva-associated lymphoid tissue (CALT) was carefully dissected out under local anesthesia and an operation microscope, fixed in $4 \%$ paraformaldehyde, dehydrated in graded ethanol, treated in xylene, infiltrated in paraffin, and embedded in paraffin. Sections of $5 \mu \mathrm{m}$ thickness were cut and mounted on coated slides, then dried at $37^{\circ} \mathrm{C}$ overnight.

\section{Histochemistry}

To display morphological characteristics, the sections were deparaffinized, rehydrated, stained in hematoxylin and eosin, and coverslipped using permount.

\section{Immunohistochemistry}

Immunohistochemistry was performed on the paraffin sections. Briefly, the sections were deparaffinized in xylene and rehydrated in graded ethanol and distilled water. The specimens were incubated in bovine serum albumin to block nonspecific binding and then incubated in primary antibody overnight. Following washing in PBS, the specimens were incubated in secondary antibody for $2-4 \mathrm{~h}$. For each staining, the specimens were also stained in parallel without the primary antibody to rule out nonspecific and background signals. Examination was done with a Lica fluorescent micro- scope. Mouse anti-CD3 monoclonal antibody (GeneTex Inc., San Antonio, TX, USA) to detect pan-T cells and mouse anti-pan-B lymphocyte antibody (VMRD, Inc., Pullman, WA, USA) to localize B cells were used. Antibody binding was identified with goat anti-mouse IgG conjugated Alexa 488.

\section{RESULTS}

\section{Morphologic characterization of CALT}

CALT could be recognized under a slit lamp without difficulty in all patients. Affected eyes showed redness and irritation with increased sensitivity to light. Gray transparent protrusions were easily found in the palpebral conjunctival region. The CALT diameter was over $1 \mathrm{~mm}$ and surrounded by proliferative blood vessels (Fig. 1).

In order to display the structural and cellular characteristics of CALT, histological staining of hematoxylin and eosin was performed. Cross-sectional views of the follicles revealed that typically no goblet cells were found within the FAE. There was a great mass of lymphocytes and macrophages in the epithelial layer so that the epithelial basement membrane was discontinuous.

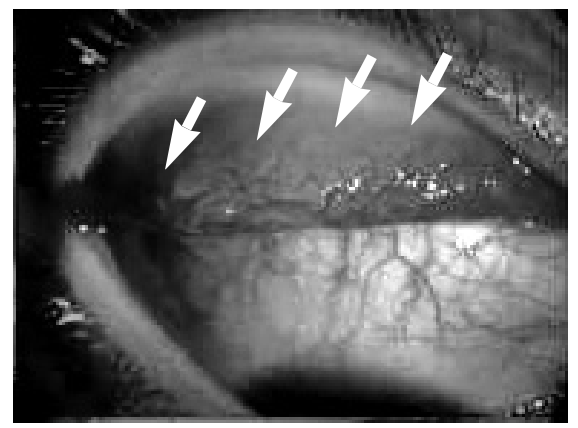

Fig. 1. Giant papillae surrounded by blood vessels on the conjunctiva of a CL-GPC patient were presented in the palpebral conjunctival area (arrowheads) with accompanying conjunctival redness.

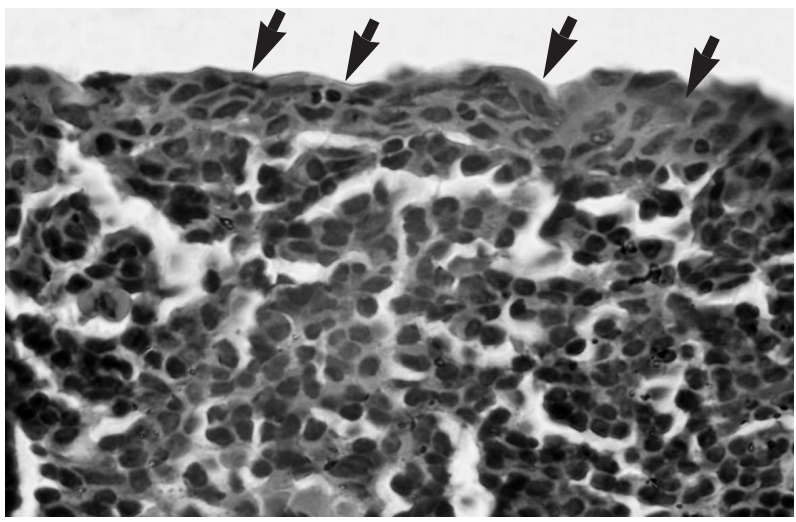

Fig. 2. HE staining revealed that lymphocytes pressed into "pockets" formed by FAE invagination (arrowheads), the apical membrane was obviously thin, and the epithelial basement membrane was not continuous. 
Moreover, lymphocytes and antigen-presenting cells were pressed into the FAE, forming intraepithelial pockets (Fig. 2).

\section{$B$ and $T$ lymphocyte distribution within CALT}

In MALT, B cells are predominantly distributed in the center of the follicle and T cells are in the parafolliclar regions to either side of the center of the follicle $[3,17,32]$. In order to recognize the distribution of $\mathrm{T}$ and B lymphocytes in CALT, we used anti-pan-B and anti-pan-T cell markers to localize the distribution. In CALT, pan-B-positive cells were mostly gathered in central folliclar area and intraepithelial pockets (Fig. 3A). However, CD3-positive cells were predominantly distributed in the parafolliclar region and there were very few CD3-positive cells in the intraepithelial pockets (Fig. 3B). This suggests that the immune response in the pathogenesis of CL-GPC is mediated by B lymphocytes.

A

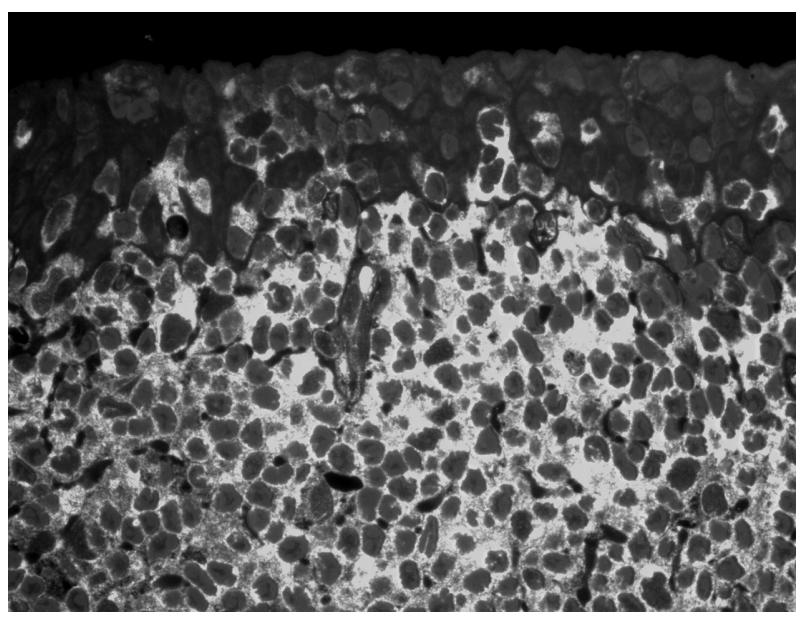

B

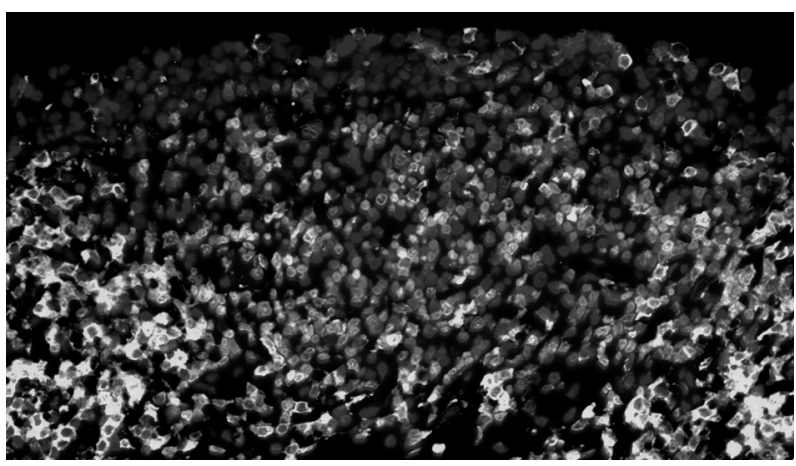

Fig 3. The distribution of lymphocytes. Gray pan-B-positive cells were mostly gathered in the lymphoid folliclar center and most lymphocytes in the "pockets" were B cells (A); gray CD3-positive T cells were predominantly distributed in the parafolliclar region (B).

\section{DISCUSSION}

The present study reveals that $\mathrm{M}$ cells are involved in the pathogenesis of CL-GPC and B cells predominantly mediate the immune response. Although the pathogenesis of CL-GPC has been studied for many years, it is still equivocal. In general, the received opinion about the mechanism is that local deposits results in CL-GPC. Significantly increased leukotriene C4 was observed in tears from patients with CL-GPC patients [13]. This local immune response may be associated with a delayed tear lens clearance and contribute to the pathogenesis or aggravate the severity of contact lens-associated papillary conjunctivitis [7].

MALT is the principal inductive site for mucosal immune responses that are capable of response to $\mathrm{T}$ and $B$ cells and specific antigens $[5,15]$. $M$ cells exist in the FAE of the top of MALT and function in the binding, uptake, and translocation of soluble and particulate antigens and pathogens. Morphologically, the basolateral membrane of the $\mathrm{M}$ cells is deeply invaginated to form intra-epithelial pockets filled with lymphocytes and macrophages so that antigens and pathogens are easily transferred to the underlying lymphocytes and dendritic cells [18, 27, 31, 37]. Recent studies revealed that mammalian conjunctiva contained a cell type with the morphological and functional characteristics of $\mathrm{M}$ cells. Typically, these cells can bind and translocate macromolecular material, bacteria, and lectin into underlying lymphocytes, and even cervical lymph nodes. It is indubitable that $M$ cells provide a route of entry into conjunctiva for antigens and pathogens $[10,18,19$, 21, 22].

Some studies indicated that contact lenses are susceptible to contamination by surface deposits. The contamination mainly includes protein and bacteria $[11,16$, $20,23]$. These deposits on the lens and ocular surface will be initially processed by the ocular surface's immune system. There is no doubt that CALT plays a key role in this step. Our results revealed that B lymphocytes and antigen-presenting cells gathered in the intraepithelial pockets and picked up the antigens and pathogens from the ocular surface. Although the biological characteristics of the $M$ cells are yet to be defined, this study represents the first attempt to distinguish that $\mathrm{M}$ cells are involved in the pathogenesis of CL-GPC. These M cells may act as the afferent limb of conjunctival specific immunity, playing an important role in the surveillance and sampling of the ocular surface. They might translocate the antigens and/or pathogens from the ocular surface into underlying $\mathrm{B}$ lymphocytes so that the B cells are stimulated, gather, proliferate in the CALT, and move to the lymph nodes, which subsequently produces an immune protective response [21]. Although sampling by $\mathrm{M}$ cells from the ocular surface is crucial for the induction of the protective conjunctival immune responses, it may also provide a way of entry into the ocular tissue for antigens and/or opportunistic pathogens so that damage to the ocular surface may occur. Studies showed that M cells do not express MHC class II molecules and have only few lysosomes; therefore, most antigens and pathogens will not be degraded when crossing $\mathrm{M}$ cells $[28,30]$. Moreover, accumulating evidence showed that the numbers of $\mathrm{M}$ 
cells are increased through the induction of mucosal inflammations, and this also happens in the conjunctiva $[4,9,14,24,33,35]$. Numerous $M$ cell formation and lymphocyte gathering produce some very large CALTs so that conjunctival structures and functions are changed. Long-term chronic inflammation may result in conjunctival scar formation, dry eye, and other severe eye diseases.

Although CALT is also found in human conjunctiva without contact lens, the diameter of non-CL-GPC follicles is smaller than $1 \mathrm{~mm}$ and physical conjunctival structures and functions are maintained, so that their existence causes no complaint [17]. However, giant conjunctival papillae resulting from over-proliferation of $\mathrm{M}$ cells and the accumulation of numerous lymphocytes give rise to conjunctival structural destruction and become the main source of clinical discomfort in patients with CL-GPC.

Acknowledgment: This work was supported by a grant from NCET (04-0812), the Natural Science Foundation of Guangdong (04105323), Fok Ying Tong Education Foundation, (91043), SRFDP (20050558075), and the National Natural Science Foundation of China (30572007).

\section{REFERENCES}

1. Allansmith M. R., Baird R. S. and Greiner J. V. (1979): Vernal conjunctivitis and contact lens-associated giant papillary conjunctivitis compared and contrasted. Am. J. Ophthalmol., 87, 544-555.

2. Allansmith M. R., Korb D. R. and Greiner J. V. (1978): Giant papillary conjunctivitis induced by hard or soft contact lens wear: quantitative histology. Ophthalmology, 85, 766-778.

3. Astley R. A., Kennedy R. C. and Chodosh J. (2003): Structural and cellular architecture of conjunctival lymphoid follicles in the baboon (Papio anubis). Exp. Eye Res., 76, 685-694.

4. Borghesi C., Regoli M., Bertelli E. and Nicoletti C. (1996): Modifications of the follicle-associated epithelium by short-term exposure to a non-intestinal bacterium. J. Pathol., 180, 326-332.

5. Brandtzaeg P. and Pabst R. (2004): Let's go mucosal: communication on slippery ground. Trends Immunol., 25, 570-577.

6. Chandler J. W. and Gillette T. E. (1983): Immunologic defense mechanisms of the ocular surface. Ophthalmology, 90, 585-591.

7. Chang S. W. and Chang C. J. (2001): Delayed tear lens clearance in contact lens associated papillary conjunctivitis. Curr. Eye Res., 22, 253-257.

8. Collins F. M. (1978): Cellular antimicrobial immunity. CRC Crit. Rev. Microbiol., 7, 27-91.

9. Cuvelier C. A., Quatacker J., Mielants H. and De Veys E. (1993): Roels H. M cells are damaged and increased in number in inflamed human ileal mucosa. Eur. J. Morphol., 31, 87-91.

10. Giuliano E. A., Moore C. P. and Phillips T. E. (2002): Morphological evidence of $\mathrm{M}$ cells in healthy canine conjunctiva-associated lymphoid tissue. Graefes Arch. Clin. Exp. Ophthalmol., 240, 220-226.
11. Hart D. E., Lane B. C., Josephson J. E., Tisdale R. R., Gzik M., Leahy R. and Dennis T. L. (1987): Spoilage of hydrogel contact lenses by lipid deposits. Ophthalmology, 94, 1315-1321.

12. Henriquez A. S. and Allansmith M. R. (1979): Russell bodies in contact-lens-associated giant papillary conjunctivitis. Arch. Ophthalmol., 97, 473-478.

13. Irkec M. T., Orhan M. and Erdener U. (1999): Role of tear inflammatory mediators in contact lens-associated giant papillary conjunctivitis in soft contact lens wearers. Ocul. Immunol. Inflamm., 7, 35-38.

14. Kaser A., Ludwiczek O., Holzmann S., Moschen A. R., Weiss G., Enrich B., Graziadei I., Dunzendorfer S., Wiedermann C. J., Mürzl E., Grasl E., Jasarevic Z., Romani N., Offner F. A. and Tilg H. (2004): Increased expression of CCL20 in human inflammatory bowel disease. J. Clin. Immunol., 24, 74-85.

15. Kiyono H. and Fukuyama S. (2004): NALT- versus Peyer's-patch-mediated mucosal immunity. Nat. Rev. Immunol., 4, 699-710.

16. Kleist F. D. (1979): Appearance and nature of hydrophilic contact lenses deposits. Part I: Protein and other organic deposits. Int. Contact Lens Clin., 6, 120-130.

17. Knop N. and Knop E. (2000): Conjunctival-associated lymphoid tissue in the human eye. Invest. Ophthalmol. Vis. Sci., 41, 1270-1279.

18. Kraehenbuhl J. P. and Neutra M. R. (2000): Epithelial M cells: differentiation and function. Annu. Rev. Cell Dev. Biol., 16, 301-332.

19. Latkovic S. (1989): Ultrastructure of M cells in the conjunctival epithelium of the guinea pig. Curr. Eye Res., 8, 751-755.

20. Lin S. T., Mandell R. B., Leahy C. D. and Newell J. O. (1991): Protein accumulation on disposable extended wear lenses. CLAO J., 17, 44-50.

21. Liu H., Meagher C. K., Moore C. P. and Phillips T. E. (2005): $\mathrm{M}$ cells in the follicle-associated epithelium of the rabbit conjunctiva preferentially bind and translocate latex beads. Invest. Ophthalmol Vis. Sci., 46, 4217-4223.

22. Meagher C. K., Liu H., Moore C. P. and Phillips T. E. (2005): Conjunctival M cells selectively bind and translocate Maackia amurensis leukoagglutinin. Exp. Eye Res., 80, 545-553.

23. Merindano M. D., Canals M., Saona C., Potau J. and Costa J. (1998): Observation of deposits on disposable contact lenses by bio-, light- and scanning electron microscopy. Cont. Lens Anterior Eye, 21, 55-59.

24. Meynell H. M., Thomas N. W., James P. S., Holland J., Taussig M. J. and Nicoletti C. (1999): Up-regulation of microsphere transport across the follicle-associated epithelium of Peyer's patch by exposure to Streptococcus pneumoniae R36a. FASEB J., 13, 611-619.

25. Neutra M. R., Frey A. and Kraehenbuhl J. P. (1996): Epithelial M cells: gateways for mucosal infection and immunization. Cell, 86, 345-348.

26. Neutra M. R. and Kraehenbuhl J. P. (1996): Cellular and molecular basis for antigen transport across epithelial barriers. In Ogra R., Mestecky J., McGhee J., Bienenstock J., Lamm M. and Strober W. (eds.): Mucosal Immunology. 2nd Edition. Academic Press, New York, pp.101-114.

27. Neutra M. R., Mantis N. J., Frey A. and Giannasca P. J. (1999): The composition and function of $M$ cell apical membranes: Implications for microbial pathogenesis. Semin. Immunol., 11, 171-181. 
28. Neutra M. R., Phillips T. L., Mayer E. L. and Fishkind D. J. (1987): Transport of membrane-bound macromolecules by $\mathrm{M}$ cells in follicle-associated epithelium of rabbit Peyer's patch. Cell Tissue Res., 247, 537-546.

29. Neutra M. R., Pringault E. and Kraehenbuhl J. P. (1996): Antigen sampling across epithelial barriers and induction of mucosal immune responses. Annu. Rev. Immunol., 14, 275-300.

30. Owen R. L. and Jones A. L. (1974): Epithelial cell specialization within human Peyer's patches: an ultrastructural study of intestinal lymphoid follicles. Gastroenterology, 66, 189-203

31. Owen R. L., Apple R. T. and Bhalla D. K. (1986): Morphometric and cytochemical analysis of lysosomes in rat Peyer's patch follicle epithelium: their reduction in volume fraction and acid phosphatase content in M cells compare to adjacent enterocytes. Anat. Rec., 216, 521-527.

32. Sacks E. H., Wieczorek R., Jakobiec F. A. and Knowles D. M. (1986): Lymphocyte subpopulations in the normal human conjunctiva: a monoclonal antibody study. Ophthalmology, 93, 1276-1283.
33. Sakimoto T., Shoji J., Inada N., Saito K., Iwasaki Y. and Sawa M. (2002): Histological study of conjunctiva-associated lymphoid tissue in mouse. Jpn. J. Ophthalmol., 46, 364-369.

34. Sarac O., Erdener U., Irkec M., Us D. and Gungen Y. (2003): Tear eotaxin levels in giant papillary conjunctivitis associated with ocular prosthesis. Ocul. Immunol. Inflamm., 11, 223-230.

35. Savidge T. C., Smith M. W., James P. S. and Alfred P. (1991): Salmonella-induced M-cell formation in germ-free Peyer patch tissue. Am. J. Pathol., 139, 177-184.

36. Trocme S. D., Kephart G. M., Allansmith M. R., Bourne W. M. and Gleich G. J. (1989): Conjunctival deposition of eosinophil granule major basic protein in vernal keratoconjunctivitis and contact lens-associated giant papillary conjunctivitis. Am. J. Ophthalmol., 108, 57-63.

37. Wassef J. S., Keren D. F. and Mailloux J. L. (1989): Role of $\mathrm{M}$ cells in initial antigen uptake and in ulcer formation in the rabbit intestinal loop model of shigellosis. Infect. Immun., 57, 858-863. 
